\title{
Early Low Cardiac Output Is Associated with Compromised Electroencephalographic Activity in Very Preterm Infants
}

\author{
CLAIRE R. WEST, ALAN M. GROVES, CHRIS E. WILLIAMS, JANE E. HARDING, JONATHAN R. SKINNER, \\ CARL A. KUSCHEL, AND MALCOLM R. BATTIN
}

\begin{abstract}
Liggins Institute [C.R.W., C.E.W., J.E.H., M.R.B.], University of Auckland, Auckland, New Zealand; Newborn Services [C.R.W., A.M.G., J.E.H., CAK., M.R.B.], National Women's Health, and Paediatric Cardiology [J.R.S.], Starship Hospital, Auckland District Health Board, Auckland, New Zealand
\end{abstract}

\begin{abstract}
Low cerebral blood flow in preterm infants has been associated with discontinuous electroencephalography (EEG) activity that in turn has been associated with poor long-term prognosis. We examined the relationships between echocardiographic measurements of blood flow, blood pressure (BP), and quantitative EEG data as surrogate markers of cerebral perfusion and function with 112 sets of paired data obtained over the first $48 \mathrm{~h}$ after birth in 40 preterm infants (24-30 wk of gestation, 510-1900 g at delivery). Echocardiographic measurements of right ventricular output (RVO) and superior vena caval (SVC) flow were performed serially. BP recordings were obtained from invasive monitoring or oscillometry. Modified cotside EEGs were analyzed for quantitative amplitude and continuity measurements. RVO $12 \mathrm{~h}$ after birth was related to both EEG amplitude at 12 and $24 \mathrm{~h}$ and continuity at $24 \mathrm{~h}$. Mean systemic arterial pressure (MAP) at 12 and $24 \mathrm{~h}$ was related to continuity at 12 and $24 \mathrm{~h}$ after birth. Multiple regression analyses revealed that $\mathrm{RVO}$ at $12 \mathrm{~h}$ was related to median EEG amplitude at $24 \mathrm{~h}$ and diastolic BP at $24 \mathrm{~h}$ was related to simultaneous EEG continuity. In addition, at $12 \mathrm{~h}$, infants in the lowest quartile for RVO measurements $(<282 \mathrm{~mL} / \mathrm{kg} / \mathrm{min})$ had lower EEG amplitude and those in the lowest quartile for MAP measurements $(<31 \mathrm{~mm} \mathrm{Hg})$ had lower EEG continuity. These results suggest a relationship between indirect measurements of cerebral perfusion and cerebral function soon after birth in preterm infants. (Pediatr Res 59: 610-615, 2006)
\end{abstract}

D espite progress in neonatal intensive care, there are no routinely available real-time bedside techniques for clinical assessment of brain function. Both conventional and modified EEGs have been used in neonatal intensive care units (NICUs) to obtain information on brain function in term and preterm infants, including quantitative electrophysiologic measurements (1-6). In preterm infants, severity of EEG abnormalities, including continuity, amplitude, symmetry, and the presence of seizures, recorded using the Oxford Medilog recorder (Oxford Medical Systems) have been correlated with later outcome (5).

Received August 16, 2005; accepted November 21, 2005.

Correspondence: Malcolm Battin, M.B.Ch.B., MRCP, Newborn Services, National Women's Health, Private Bag 92 024, Auckland, New Zealand; e-mail: malcolmb@adhb.govt.nz

Claire West was supported by a University of Auckland Senior Health Research Scholarship. Alan Groves was supported by Starship Foundation as Starship Foundation Southern Trust Research Fellow in Neonatal Paediatrics.

DOI: 10.1203/01.pdr.0000203095.06442.ad
EEG activity can be influenced by cerebral substrate supply. Low cerebral blood flow, measured by i.v. ${ }^{133} \mathrm{Xe}$ clearance, has been associated with discontinuous EEG activity in preterm infants (7). In preterm lambs, EEG activity deteriorated when cerebral oxygen supply decreased below a threshold level (8), and in fetal sheep, there were changes in quantitative EEG parameters after an interruption of cerebral perfusion (9).

Echocardiographic measurements of ventricular output and SVC venous return have been assessed as surrogate markers of cerebral perfusion. In early postnatal life, estimates of left ventricular output (LVO) and RVO are confounded by ductal and atrial shunts, respectively. Ductal shunting is thought to be more significant than atrial shunting, so that RVO may be a more reliable indicator of systemic perfusion than LVO (10) because it is primarily influenced by systemic venous return. Low SVC flow in the first $24 \mathrm{~h}$ after birth has been associated with periventricular hemorrhage (11) and adverse neurodevelopmental outcome at 3 y (12) and was a stronger predictor of adverse outcome than arterial blood pressure (12). However, there are no reports of the relationship between echocardiographic measurements of blood flow and EEG parameters in newborns.

This study aimed to examine the relationship between echocardiographic flow data, routinely obtained cardiovascular measurements, and quantitative EEG data obtained over the first $48 \mathrm{~h}$ after birth in preterm infants.

\section{METHODS}

Infants born before $31 \mathrm{wk}$ of gestation and admitted to National Women's Hospital, Auckland, New Zealand, between January 1, 2003, and January 31, 2004 were eligible for recruitment. Infants reported here were recruited for two different studies: serial echocardiography over the first $48 \mathrm{~h}$ after birth to assess a variety of hemodynamic measurements including SVC flow and RVO and two to four EEGs in the first week after birth to document the temporal changes in quantitative EEG measurements. Infants had simultaneous EEG and echocardiography measurements whenever possible. The Auckland Ethics Committee approved both studies. Parents of eligible infants

Abbreviations BP, blood pressure; LVO, left ventricular output; MAP, mean systemic arterial pressure; RVO, right ventricular output; SVC, superior vena cava 
were approached either before or as soon as possible after delivery and informed parental consent was obtained. Recording and analysis of echocardiographic and EEG assessments were performed by independent observers unaware of the other's results.

Echocardiography was performed as close as possible to 5, 12, 24, and 48 $\mathrm{h}$ after birth, at the time of routine nursing care to minimize handling. All echocardiographic recordings were made by one of two investigators (A.M.G. and C.A.K.). SVC flow volume was assessed as described by Kluckow et al. (13). SVC diameter was assessed using an M mode trailing edge-leading edge technique from a high parasternal view where the vessel begins to open up into the right atrium. Maximum and minimum vessel diameters were assessed in five consecutive cardiac cycles, and the mean of these 10 measurements taken to be the mean SVC diameter. SVC flow velocity was assessed using pulsed wave Doppler from a low subcostal view with the Doppler range gate where the vessel begins to open up into the right atrium. Measurements of SVC flow were averaged over 10 consecutive cardiac cycles to minimize the impact of respiratory variation in flow. Any reversed flow in the SVC was quantified and deducted from the measured forward flow.

RVO diameter was assessed by frame-by-frame analysis of the twodimensional image at the hinge points of the pulmonary valve from either the parasternal short axis or tilted parasternal long axis views during cardiac systole (14). Pulmonary systolic velocity-time integral (VTI) was assessed using pulsed wave Doppler, with the range gate placed at the tips of the pulmonary valve leaflets when viewed from the parasternal short axis view (14).

Volume of flow $(\mathrm{mL} / \mathrm{kg} / \mathrm{min})$ was calculated from the following: [VTI $\times$

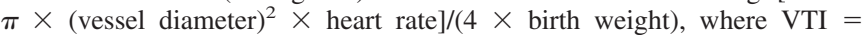
velocity time integral in $\mathrm{cm}, \pi=3.14159$, vessel diameter in centimeters, birth weight in kilograms (13).

Infants with invasive BP monitoring had recordings downloaded routinely every $60 \mathrm{~s}$ using Marquette Solar 8000 monitors (GE Medical Systems) and Bedmaster V1.3 software (Excel Medical Electronics Inc.). These BP measurements were averaged over the duration of the echocardiography. Intermittent BP measurements obtained by oscillometry, using the Marquette monitors with appropriately sized cuffs, were only included if invasive BP readings were not available and if BP readings were taken within an hour of the echocardiogram. The protocol in our unit was that infants with MAP below $30 \mathrm{~mm} \mathrm{Hg}$ received an initial $10 \mathrm{~mL} / \mathrm{kg}$ bolus of normal saline. Those whose MAP remained below $30 \mathrm{~mm} \mathrm{Hg}$ were commenced on dopamine infusion $5-10 \mu \mathrm{g} \cdot \mathrm{kg}^{-1} \cdot \mathrm{min}^{-1}$, titrated to the BP responses.

EEGs were recorded two to four times during the first week after birth using the research BRM bedside monitor (BrainZ Instruments Ltd., Auckland, New Zealand) using hydrogel electrodes (Hydrospot neonatal electrodes, Physiometrix Inc., North Billerica, MA) placed on the C3, P3, C4, and P4 regions defined by the modified international 10-20 system after skin preparation appropriate to gestational age (Nuprep, D O Weaver \& Co., Aurora, $\mathrm{CO}$ ) and held in position by hydrogel tape (Klear-Tape, Cas Medical Systems, Branford, CT). All EEG recordings were obtained by one investigator (C.R.W.). EEGs were recorded over 2- to 12-h periods. The averaged signals were analyzed offline using customized software (Chart Analyser, Liggins Institute, Auckland, New Zealand). EEG data were included in the analyses if the electrode impedance was $<15 \mathrm{k} \Omega$ per pair.

Quantitative neurophysiologic measurements of median and minimum amplitude, and continuity were assessed as median values for the $60 \mathrm{~min}$ immediately before or after the echocardiogram was performed. Left- and right-sided values were averaged. Amplitude was calculated from the bandpass filtered and rectified signal with an algorithm that generates minimum, maximum, and median amplitudes that are functionally equivalent to the Cerebral Function Monitor (15). Continuity measurements were determined as the percentage of each minute during which the amplitude of the raw EEG (assessed at 2-s intervals) was above the determined threshold amplitude (10, 25 , or $50 \mu \mathrm{V}$ ).

Simple linear regression was performed for continuous variables that approximated a normal distribution. First, analyses were performed between flow/BP measurements and EEG measurements obtained at each time point. Second, analyses were performed between flow/BP measurements at one time point with EEG measurements over the following $24 \mathrm{~h}$. Analyses with two-tailed $p$ values $\leq 0.05$ were included in multiple regression analysis using the following independent variables: gestation, birthweight $Z$ score, and CRIB-II score (16). To further explore the strength of the relationships between measurements of cardiovascular function and EEG, we also compared EEG measurements between infants having the lowest quartile of blood flow or pressure measurements at each time point and the remainder of the cohort. As these measurements were not normally distributed, they were compared using the Mann-Whitney $U$ test. Statistical analyses were performed using Statview version 5.0.1 (SAS Institute Inc.). Values are reported as median (range).

\section{RESULTS}

During the study period, 155 infants were admitted to the NICU at less than 30 wk of completed gestation. Forty infants had at least one set of paired EEG and blood flow recordings, and 18 had EEG recordings in association with each of their four echocardiograms. Their median (range) gestation was 27 (24-30) wk, and birthweight was 945 (510-1900) g (Table 1). A total of 112 sets of paired data were analyzed. Echocardiographic flow measurements, BP, and quantitative EEG parameters were all obtained in $24-30$ babies at each time period (Tables 1 and 2).

No infants were receiving opiate infusions, muscle relaxants, or sedative medication at the time of these measurements. One infant received a fentanyl bolus for intubation $3 \mathrm{~h}$ before the 12-h echocardiogram and one infant received surfactant immediately after the 5-h echocardiogram, at the start of the EEG assessment period. These two infants remained in the analyses as their exclusion did not change the results. The ductus arteriosus was closed in $0,4,9$, and 12 infants at 5, 12, 24 , and $48 \mathrm{~h}$. No infants received indomethacin before the 48-h assessment.

Table 1. Gestation, birth weight, patent ductus arteriosus size, ventilatory and BP support, and method of BP measurement for infants with paired flow/BP and EEG data at each time point

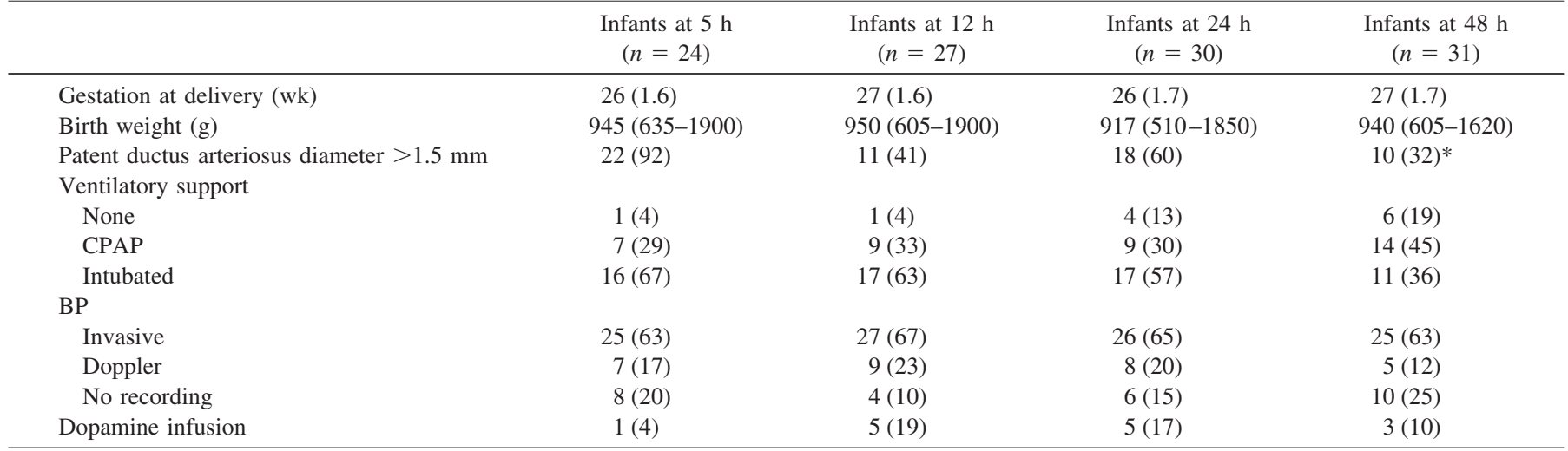

Results are mean (SD), median (range), or number (\%). CPAP, continuous positive airway pressure.

* Twelve $(30 \%)$ of infants had closed ductus arteriosus. 
Table 2. Echocardiographic flow measurements, BP, and quantitative EEG parameters

\begin{tabular}{lcccc}
\hline & $5 \mathrm{~h}$ & $12 \mathrm{~h}$ & $24 \mathrm{~h}$ & $48 \mathrm{~h}$ \\
\hline SVC flow $(\mathrm{mL} / \mathrm{kg} / \mathrm{min})$ & $89(34-186)[n=40]$ & $97(21-183)[n=39]$ & $91(45-169)[n=38]$ & $108(45-179)[n=40]$ \\
RVO $(\mathrm{mL} / \mathrm{kg} / \mathrm{min})$ & $330(100-616)[n=38]$ & $345(161-628)[n=40]$ & $426(192-650)[n=37]$ & $411(135-655)[n=38]$ \\
MAP $(\mathrm{mm} \mathrm{Hg})$ & $35(24-49)[n=32]$ & $35(22-52)[n=36]$ & $36(25-59)[n=34]$ & $38(26-55)[n=30]$ \\
Systolic BP $(\mathrm{mm} \mathrm{Hg})$ & $44(28-67)[n=32]$ & $44(28-66)[n=36]$ & $46(33-67)[n=34]$ & $51(35-71)[n=30]$ \\
Diastolic BP (mm Hg) & $26(16-38)[n=32]$ & $27(18-43)[n=36]$ & $27(19-47)[n=34]$ & $30(20-45)[n=30]$ \\
Continuity at $10-\mu \mathrm{V}$ threshold $(\% / \mathrm{min})$ & $100(56-100)[n=24]$ & $100(69-100)[n=27]$ & $100(91-100)[n=30]$ & $100(94-100)[n=31]$ \\
Continuity at $25-\mu \mathrm{V}$ threshold $(\% / \mathrm{min})$ & $59(25-95)[n=24]$ & $64(29-100)[n=27]$ & $78(52-97)[n=30]$ & $88(50-100)[n=31]$ \\
Continuity at $50-\mu \mathrm{V}$ threshold $(\% / \mathrm{min})$ & $27(11-64)[n=24]$ & $29(12-85)[n=27]$ & $45(15-71)[n=30]$ & $59(23-80)[n=31]$ \\
Minimum amplitude $(\mu \mathrm{V})$ & $1.9(1.2-4.4)[n=24]$ & $2.1(1.0-6.5)[n=27]$ & $2.3(1.1-6.9)[n=30]$ & $2.4(1.3-3.8)[n=31]$ \\
Median amplitude $(\mu \mathrm{V})$ & $5.3(2.6-9.4)[n=24]$ & $5.0(2.5-11.4)[n=27]$ & $6.6(3.1-11.9)[n=30]$ & $7.4(3.8-11.9)[n=31]$ \\
\hline
\end{tabular}

Values are median (range).

\section{Blood Flow}

Relationships between blood flow and EEG amplitude. $\mathrm{RVO}$ at $12 \mathrm{~h}$ was positively related to both minimum and median amplitude at $12 \mathrm{~h}\left(r^{2}=0.29, p=0.002\right.$, Fig. $1 A$ and $r^{2}=0.18, p=0.02$, respectively) and also at $24 \mathrm{~h}\left(r^{2}=0.12\right.$, $p=0.03$, Fig. $1 B$ and $r^{2}=0.20, p=0.009$, respectively). There were no significant relationships between RVO at 5, 24, or $48 \mathrm{~h}$ and EEG amplitude measurements.

SVC flow was not related to EEG amplitude at any of the time points measured.

Relationships between blood flow and EEG continuity. Only small numbers of infants had EEG continuity at $10 \mu \mathrm{V}$ $<100 \%$ : $10 / 24$ at $5 \mathrm{~h}, 10 / 27$ at $12 \mathrm{~h}, 7 / 30$ at $24 \mathrm{~h}$, and $2 / 31$ at $48 \mathrm{~h}$. As these data were not normally distributed, we did not perform linear regression analyses at this threshold.

RVO at $5 \mathrm{~h}$ was positively related to EEG continuity at the $25 \mu \mathrm{V}$ threshold at $24 \mathrm{~h}\left(r^{2}=0.11, p=0.05\right)$. RVO at $12 \mathrm{~h}$ was positively related to continuity at the $25 \mu \mathrm{V}$ threshold at $24 \mathrm{~h}\left(r^{2}=0.15, p=0.02\right)$. RVO at 24 and $48 \mathrm{~h}$ were not related to EEG continuity.

SVC flow at $5 \mathrm{~h}$ was positively related to EEG continuity at the $50 \mu \mathrm{V}$ threshold at $24 \mathrm{~h}\left(r^{2}=0.11, p=0.04\right)$. SVC flows at 12,24 , and $48 \mathrm{~h}$ were not related to EEG continuity.

\section{BP}

Approximately two thirds of the infants at each time point had invasive BP monitoring (Table 1). Invasive BP measurements were lower than those obtained noninvasively, largely because invasive monitoring was undertaken in smaller babies. When gestational age was taken into account, the only significant difference between BP measurements in the inva-
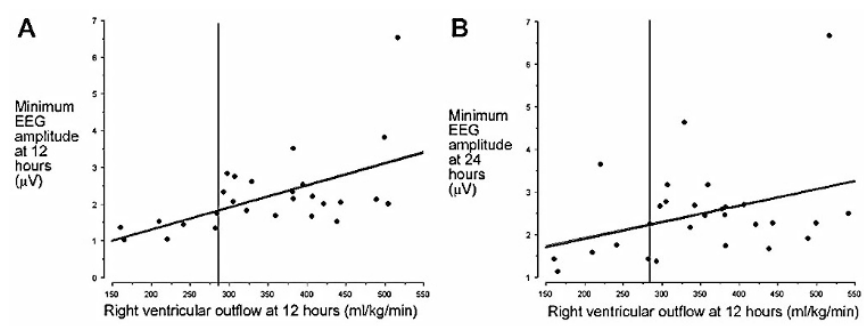

Figure 1. Relationship between RVO at $12 \mathrm{~h}$ and minimum EEG amplitude measurements at $12 \mathrm{~h}(A)\left(n=27, r^{2}=0.31\right)$ and $24 \mathrm{~h}(B)\left(n=30, r^{2}=\right.$ $0.15)$, with vertical line indicating cutoff for lowest quartile of outflow measurements $(<282 \mathrm{~mL} / \mathrm{kg} / \mathrm{min})$. sive and noninvasively monitored group was for mean $\mathrm{BP}$ at $12 \mathrm{~h}(33.5$ and $40.8 \mathrm{~mm} \mathrm{Hg}$, respectively, $p=$ 0.02).

Relationships between blood pressure and EEG amplitude. Systolic BP, diastolic BP, and MAP were not related to EEG amplitude at any time point.

Relationships between $\mathrm{BP}$ and $\mathrm{EEG}$ continuity. MAP at $12 \mathrm{~h}$ was positively related to EEG continuity at both the 25and $50 \mu \mathrm{V}$ thresholds at $12 \mathrm{~h}\left(r^{2}=0.24, p=0.008\right)$ (Fig. $2 A$ and $r^{2}=0.16, p=0.03$ ) (Fig. $2 B$, respectively). MAP at $24 \mathrm{~h}$ was related to EEG continuity at the $50 \mu \mathrm{V}$ threshold at $48 \mathrm{~h}$ $\left(r^{2}=0.13, p=0.04\right)$. MAP at 5 and $48 \mathrm{~h}$ was not related to EEG continuity.

Systolic BP was not related to EEG continuity at any time point. Diastolic BP at $24 \mathrm{~h}$ was related to EEG continuity at both $25 \mu \mathrm{V}$ and $50 \mu \mathrm{V}$ thresholds at $24 \mathrm{~h}\left(r^{2}=0.19, p=0.02\right.$ and $r^{2}=0.21, p=0.01$, respectively), and also to EEG continuity at the $50 \mu \mathrm{V}$ threshold at $48 \mathrm{~h}\left(r^{2}=0.18, p=\right.$ 0.02). Diastolic BP at 5,12 , and $48 \mathrm{~h}$ was not related to EEG continuity.

Multiple regression analyses. To explore whether these relationships were simply reflecting severity of neonatal illness, we undertook multiple regression analysis for each of the significant simple regressions, taking into account gestational age, birth weight $Z$ score, and CRIB-II score. Within the narrow range of gestations in this cohort, only continuity measures at the $25 \mu \mathrm{V}$ threshold at $12 \mathrm{~h}$ after birth was significantly related to gestational age on univariate analysis $\left(r^{2}=0.22, p=0.01\right)$, so that colinearity was not considered an important confounder in these analyses.

RVO measured at $12 \mathrm{~h}$ remained independently related to median amplitude measured at $24 \mathrm{~h}$ (overall $\mathrm{r}^{2}=0.24, p=$
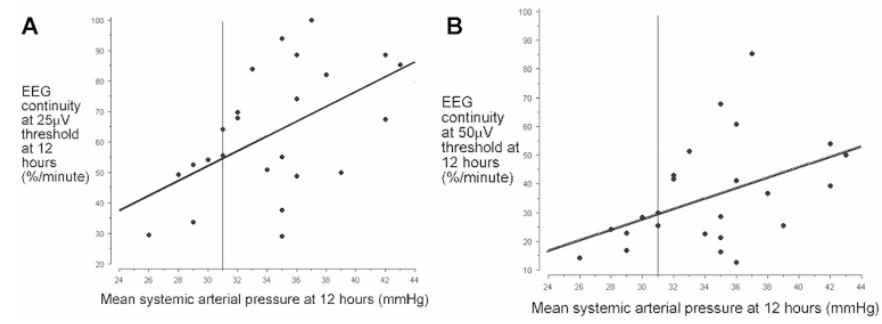

Figure 2. Relationship between mean systemic arterial blood pressure at $12 \mathrm{~h}$ and EEG continuity measurements at $12 \mathrm{~h}$ at the $25 \mu \mathrm{V}(A)(n=27$, $\left.r^{2}=0.28\right)$ and $50 \mu \mathrm{V}(B)\left(n=27, r^{2}=0.20\right)$ thresholds, with vertical line indicating cutoff for lowest quartile of pressure measurements $(<31 \mathrm{~mm} \mathrm{Hg})$. 
0.04$, RVO $p=0.01)$. The relationships between diastolic BP at $24 \mathrm{~h}$ and EEG continuity measured at both the 25 and 50 $\mu \mathrm{V}$ thresholds at $24 \mathrm{~h}$ also remained significant in multiple regression models (overall $r^{2}=0.38, p=0.01$ with diastolic BP $p=0.003$, and $r^{2}=0.55, p=0.0008$ with diastolic BP $p=0.0003$, respectively).

Lowest blood flow quartile and EEG parameters. Infants in the lowest quartile for RVO at $12 \mathrm{~h}$ had lower minimum and median amplitude at $12 \mathrm{~h}(p=0.006$ and $p=0.0003$, respectively; table 3$)$ and at $24 \mathrm{~h}(p=0.001$ and $p=0.005$, respectively; table 3 ). Infants in the lowest quartile for RVO at $5 \mathrm{~h}(<249 \mathrm{~mL} / \mathrm{kg} / \mathrm{min})$ and at $24 \mathrm{~h}(<349 \mathrm{~mL} / \mathrm{kg} / \mathrm{min}) \mathrm{did}$ not differ from the remainder of the cohort in EEG amplitude.

Infants in the lowest quartile for RVO at $5 \mathrm{~h}$ had lower EEG continuity at the $10 \mu \mathrm{V}$ threshold at $24 \mathrm{~h}$ [median (range), $97 \%(91-100 \%)$ cf. 100\% (94-100\%), $p=0.03$ ]. Infants in the lowest quartile for RVO at $12 \mathrm{~h}$ had lower EEG continuity at the 10,25 , and $50 \mu \mathrm{V}$ threshold at $12 \mathrm{~h}(p=0.02, p=0.03$, and $p=0.08$, respectively; Table 3$)$ and at $24 \mathrm{~h}(p=0.0003$, $p=0.01$ and $p=0.03$, respectively; Table 3 ). Infants in the lowest quartile for RVO at $24 \mathrm{~h}$ did not differ from the remainder of the cohort in EEG continuity.

At all times studied, infants in the lowest quartile for SVC flow did not differ from the remainder of the cohort for EEG amplitude. However, infants in the lowest quartile for SVC flow at $5 \mathrm{~h}(<63 \mathrm{~mL} / \mathrm{kg} / \mathrm{min})$ had lower EEG continuity at the $10 \mu \mathrm{V}$ threshold at $24 \mathrm{~h}$ [median (range], 98\% (91-100\%) $c f$. $100 \%(96-100 \%) ; p=0.01]$. Infants in the lowest quartile for SVC flow at $12 \mathrm{~h}(<64 \mathrm{~mL} / \mathrm{kg} / \mathrm{min})$ also had lower EEG continuity at the $10 \mu \mathrm{V}$ threshold at $24 \mathrm{~h}$ [median (range),
96\% (91-100\%) cf. 100\% (96-100\%), $p=0.02]$. Infants in the lowest quartile for SVC flow at $24 \mathrm{~h}(<77 \mathrm{~mL} / \mathrm{kg} / \mathrm{min}) \mathrm{did}$ not differ from the remainder of the cohort for EEG continuity.

Lowest BP quartile and EEG parameters. Infants in the lowest quartile for MAP at $12 \mathrm{~h}$ had a lower median amplitude at $12 \mathrm{~h}(p=0.01$; Table 3). Infants in the lowest quartile for MAP at $5 \mathrm{~h}(<30 \mathrm{~mm} \mathrm{Hg})$ and at $24 \mathrm{~h}(<32 \mathrm{~mm} \mathrm{Hg})$ did not differ from the remainder of the cohort for EEG amplitude.

Infants in the lowest quartile for MAP at $5 \mathrm{~h}$ had lower EEG continuity at the $25 \mu \mathrm{V}$ threshold at $24 \mathrm{~h}$ [median (range), $61 \mathrm{~mm} \mathrm{Hg}(56-78 \mathrm{~mm} \mathrm{Hg}) c f .82(52-97 \mathrm{~mm} \mathrm{Hg}), p=0.02]$. Infants in the lowest quartile for MAP at $12 \mathrm{~h}$ had lower EEG continuity at the 10,25 , and $50 \mu \mathrm{V}$ thresholds at $12 \mathrm{~h}(p=$ $0.003, p=0.02$ and $p=0.03$, respectively; Table 3). Infants in the lowest quartile for MAP at $24 \mathrm{~h}$ did not differ from the remainder of the cohort for EEG continuity.

Infants in the lowest quartile for diastolic BP at $5 \mathrm{~h}$ $(<23 \mathrm{~mm} \mathrm{Hg}$ ) did not differ from the remainder of the cohort for EEG amplitude. However, infants in the lowest quartile for diastolic BP at $12 \mathrm{~h}$ had lower median amplitude at $12 \mathrm{~h}$ $(p=0.04$; Table 3). Similarly, infants in the lowest quartile for diastolic BP at $24 \mathrm{~h}(<25 \mathrm{~mm} \mathrm{Hg})$ had lower minimum and median amplitude at $24 \mathrm{~h}$ [(median (range), $1.5 \mu \mathrm{V}$ $(1.1-2.2 \mu \mathrm{V}) c f .2 .5 \mu \mathrm{V}(1.4-6.7 \mu \mathrm{V}), p=0.007]$ and $48 \mathrm{~h}$ [1.9 $\mu \mathrm{V}(1.3-2.0 \mu \mathrm{V}) c f .2 .5 \mu \mathrm{V}(1.5-3.8 \mu \mathrm{V}), p=0.03]$.

Infants in the lowest quartile for diastolic BP at $12 \mathrm{~h}$ had lower EEG continuity at the $50 \mu \mathrm{V}$ threshold at $12 \mathrm{~h}(p=$ 0.04; Table 3). Infants in the lowest quartile for diastolic BP at $24 \mathrm{~h}$ had lower EEG continuity at the 25 and $50 \mu \mathrm{V}$ thresholds at $24 \mathrm{~h}$ [median (range), $65 \%$ (56-78\%) cf. 79\%

Table 3. Comparison between quantitative EEG measurements in infants in the lowest quartile of right ventricular outflow and blood pressure 12 hours after birth and the remainder of the study cohort

\begin{tabular}{|c|c|c|c|c|c|c|c|c|c|c|c|}
\hline & & & & & & \multicolumn{6}{|c|}{ Continuity thresholds (\%/min) } \\
\hline & & \multicolumn{2}{|c|}{ Minimum amplitude $(\mu \mathrm{V})$} & \multicolumn{2}{|c|}{ Median amplitude $(\mu \mathrm{V})$} & \multicolumn{2}{|c|}{$10 \mu \mathrm{V}$} & \multicolumn{2}{|c|}{$25 \mu \mathrm{V}$} & \multicolumn{2}{|c|}{$50 \mu \mathrm{V}$} \\
\hline & & $12 \mathrm{~h}$ & $24 \mathrm{~h}$ & $12 \mathrm{~h}$ & $24 \mathrm{~h}$ & $12 \mathrm{~h}$ & $24 \mathrm{~h}$ & $12 \mathrm{~h}$ & $24 \mathrm{~h}$ & $12 \mathrm{~h}$ & $24 \mathrm{~h}$ \\
\hline \multicolumn{12}{|l|}{ RVO $12 \mathrm{~h}$} \\
\hline $\begin{array}{l}\text { Lowest quartile } \\
(<282 \mathrm{~mL} / \mathrm{kg} / \mathrm{min})\end{array}$ & $\begin{array}{c}1.3 * \\
(1.0-1.5) \\
(n=6)\end{array}$ & $\begin{array}{l}1.5^{*} \\
(1.1-3.7) \\
(n=8)\end{array}$ & $\begin{array}{c}3.3^{*} \\
(2.5-5.0) \\
(n=6)\end{array}$ & $\begin{array}{c}4.6^{*} \\
(3.8-7.6) \\
(n=8)\end{array}$ & $\begin{array}{c}84 * \\
(69-100) \\
(n=6)\end{array}$ & $\begin{array}{c}96^{*} \\
(91-100) \\
(n=8)\end{array}$ & $\begin{array}{c}42 * \\
(29-68) \\
(n=6)\end{array}$ & $\begin{array}{c}64 * \\
(56-96) \\
(n=8)\end{array}$ & $\begin{array}{c}20 \\
(14-42) \\
(n=6)\end{array}$ & $\begin{array}{c}31 * \\
(26-63) \\
(n=8)\end{array}$ & \\
\hline $\begin{array}{l}\text { Remainder } \\
(\geq 282 \mathrm{~mL} / \mathrm{kg} / \mathrm{min})\end{array}$ & $\begin{array}{c}2.2 \\
(1.5-6.5) \\
(n=21)\end{array}$ & $\begin{array}{c}2.5 \\
(1.3-6.7) \\
(n=22)\end{array}$ & $\begin{array}{c}5.1 \\
(3.4-11.4) \\
(n=21)\end{array}$ & $\begin{array}{c}7.4 \\
(3.1-11.9) \\
(n=22)\end{array}$ & $\begin{array}{l}100 \\
(91-100) \\
(n=21)\end{array}$ & $\begin{array}{c}100 \\
(94-100) \\
(n=22)\end{array}$ & $\begin{array}{c}67 \\
(29-100) \\
(n=21)\end{array}$ & $\begin{array}{c}79 \\
(52-97) \\
(n=22)\end{array}$ & $\begin{array}{c}37 \\
(12-85) \\
(n=21)\end{array}$ & $\begin{array}{c}52 \\
(15-71) \\
(n=22)\end{array}$ & \\
\hline \multicolumn{12}{|l|}{ MAP $12 \mathrm{~h}$} \\
\hline $\begin{array}{l}\text { Lowest quartile } \\
\text { (<31 mm Hg) }\end{array}$ & $\begin{array}{l}1.7 \\
(1.0-2.1) \\
(n=5)\end{array}$ & $\begin{array}{c}2.0 \\
(1.1-2.7) \\
(n=6)\end{array}$ & $\begin{array}{c}4.1 \\
(2.8-4.6) \\
(n=5)\end{array}$ & $\begin{array}{c}5.2 * \\
(4.5-9.7) \\
(n=6)\end{array}$ & $\begin{array}{c}91 * \\
(69-96) \\
(n=5)\end{array}$ & $\begin{array}{l}100 \\
(91-100) \\
(n=6)\end{array}$ & $\begin{array}{c}29 * \\
(12-85) \\
(n=5)\end{array}$ & $\begin{array}{c}69 \\
(56-90) \\
(n=6)\end{array}$ & $\begin{array}{c}23 * \\
(14-28) \\
(n=5)\end{array}$ & $\begin{array}{c}36 \\
(31-67) \\
(n=6)\end{array}$ & \\
\hline $\begin{array}{l}\text { Remainder } \\
(\geq 31 \mathrm{~mm} \mathrm{Hg})\end{array}$ & $\begin{array}{c}2.1 \\
(1.0-6.5) \\
(n=19)\end{array}$ & $\begin{array}{c}2.3 \\
(1.4-6.7) \\
(n=21)\end{array}$ & $\begin{array}{c}5.1 \\
(2.5-11.4) \\
(n=19)\end{array}$ & $\begin{array}{c}6.7 \\
(3.1-11.9) \\
(n=21)\end{array}$ & $\begin{array}{c}100 \\
(70-100) \\
(n=19)\end{array}$ & $\begin{array}{c}100 \\
(93-100) \\
(n=21)\end{array}$ & $\begin{array}{c}49 \\
(30-54) \\
(n=19)\end{array}$ & $\begin{array}{c}78 \\
(52-97) \\
(n=21)\end{array}$ & $\begin{array}{c}39 \\
(13-85) \\
(n=19)\end{array}$ & $\begin{array}{c}52 \\
(15-71) \\
(n=21)\end{array}$ & \\
\hline \multicolumn{12}{|l|}{ DBP $12 \mathrm{~h}$} \\
\hline $\begin{array}{l}\text { Lowest quartile } \\
(<25 \mathrm{~mm} \mathrm{Hg})\end{array}$ & $\begin{array}{c}2.0 \\
(1.3-2.3) \\
(n=7)\end{array}$ & $\begin{array}{l}1.9 \\
(1.4-2.7) \\
(n=7)\end{array}$ & $\begin{array}{c}4.1 \\
(2.8-5.0) \\
(n=7)\end{array}$ & $\begin{array}{c}5.1 \\
(3.1-9.7) \\
(n=7)\end{array}$ & $\begin{array}{c}96^{*} \\
(69-100) \\
(n=7)\end{array}$ & $\begin{array}{c}100 \\
(94-100) \\
(n=7)\end{array}$ & $\begin{array}{c}53^{*} \\
(30-68) \\
(n=7)\end{array}$ & $\begin{array}{c}68 \\
(52-90) \\
(n=7)\end{array}$ & $\begin{array}{c}24 * \\
(13-42) \\
(n=7)\end{array}$ & $\begin{array}{c}35 \\
(15-67) \\
(n=7)\end{array}$ & \\
\hline $\begin{array}{l}\text { Remainder } \\
(\geq 25 \mathrm{~mm} \mathrm{Hg})\end{array}$ & $\begin{array}{l}2.2 \\
(1.0-6.5) \\
(n=17)\end{array}$ & $\begin{array}{c}2.4 \\
(1.1-6.7) \\
(n=20)\end{array}$ & $\begin{array}{c}5.2 \\
(2.5-11.4) \\
(n=17)\end{array}$ & $\begin{array}{c}7.1 \\
(3.8-11.9) \\
(n=20)\end{array}$ & $\begin{array}{c}100 \\
(70-100) \\
(n=17)\end{array}$ & $\begin{array}{c}100 \\
(91-100) \\
(n=20)\end{array}$ & $\begin{array}{c}70 \\
(29-100) \\
(n=17)\end{array}$ & $\begin{array}{c}79 \\
(56-97) \\
(n=20)\end{array}$ & $\begin{array}{c}39 \\
(16-85) \\
(n=17)\end{array}$ & $\begin{array}{c}52 \\
(24-71) \\
(n=20)\end{array}$ & \\
\hline
\end{tabular}

Results are median (range).

$* p<0.05$ lowest quartile compared with remainder.

DPB, diastolic BP. 
(52-97\%), $p=0.02$ and $31 \%(26-46 \%)$ cf. 52\% (15-67\%), $p=0.05$, respectively]. Infants in the lowest quartile for diastolic BP at $5 \mathrm{~h}$ did not differ from the remainder of the cohort for EEG continuity.

\section{DISCUSSION}

This study demonstrates that, in the newborn preterm infant, some blood flow and BP measurements are related to quantitative EEG measurements, both simultaneously and 12-24 h later. In particular, RVO measured $12 \mathrm{~h}$ after birth was related to both EEG amplitude and continuity at 12 and $24 \mathrm{~h}$ after birth, and BP measurements at 12 and $24 \mathrm{~h}$ were also related to EEG continuity at 12 and $24 \mathrm{~h}$ after birth. These findings are interesting as discontinuous EEG traces, low RVO, and SVC flow have all been associated with increased risk of significant intraventricular hemorrhage and poor neurodevelopmental outcome $(6,11,12,17)$.

Although this study reports findings from a small number of infants, we demonstrated significant relationships between EEG and physiologic measurements. These analyses are only exploratory, and we have performed a large number of comparisons to generate the hypotheses and to test the findings. However, these different analytical approaches all showed consistent relationships. Multiple regression analyses suggested that the relationships found were not just because the smallest, youngest, and sickest babies had the lowest blood flow, BP, and quantitative EEG measurements.

Conventional multichannel EEG recordings remain the gold-standard method of assessing cerebral activity, but are difficult to perform in extremely preterm infants; hence, new cotside devices are increasingly used. In preterm infants, EEG amplitude measured on Cerebral Function Monitor traces obtained shortly after birth can predict later outcome of infants with grade 3 or 4 intraventricular hemorrhage (18). Our data show that infants with the lowest RVO at $12 \mathrm{~h}$ of age tended to have lower EEG amplitudes at 12 and $24 \mathrm{~h}$, raising the possibility that this group may also include those at greatest risk of an adverse long-term outcome.

EEG continuity may be potentially useful in clinical practice. Extremely preterm infants have discontinuous EEG traces that become more continuous with increasing gestation (19). In encephalopathic term infants, persisting EEG discontinuity is associated with adverse neurodevelopmental outcome (20). Our data show that infants with lower RVO at $12 \mathrm{~h}$ and also those with lowest quartile of MAP and diastolic BP at 12 and $24 \mathrm{~h}$ had more discontinuous EEGs at 12 and $24 \mathrm{~h}$, again consistent with the possibility that this group includes infants at greater risk.

Amplitude thresholds ranging from 5 to $45 \mu \mathrm{V}(6,21)$ have been used to assess discontinuity and interburst interval in EEGs from newborn infants. It is not yet clear which threshold has the most utility for predicting outcome. We therefore examined continuity data at 10,25 , and $50 \mu \mathrm{V}$ thresholds using the BRM monitor's continuity algorithm to examine the effects of blood flow and pressure parameters on different levels of EEG attenuation. Our data show similar effects across these thresholds, indicating that these findings are not isolated to the most discontinuous traces.

Our data suggest that the relationships between blood flow, $\mathrm{BP}$, and quantitative EEG measurements are most evident between 12 and $24 \mathrm{~h}$ after delivery. The paucity of relationships found at $5 \mathrm{~h}$ may in part be related to the profound circulatory, metabolic, and neurologic changes occurring in the period soon after birth. By $12 \mathrm{~h}$, the infant has usually stabilized and any underlying relationship between perfusion and cerebral activity may become more apparent.

Human and animal data support our finding that changes in cerebral perfusion can be related to concurrent EEG changes $(7,9,22)$. However, we found that RVO at $12 \mathrm{~h}$ was also related to EEG amplitude and continuity at $24 \mathrm{~h}$ after birth. There are two possible explanations for this apparent delay. First, the infants with low RVO and EEG changes at $12 \mathrm{~h}$ may have been the same infants who had low RVO and EEG changes at $24 \mathrm{~h}$, resulting in an apparent relationship between the two time points. We were unable to fully explore this possibility as we had too few infants with RVO and EEG data at both 12 and $24 \mathrm{~h}$. However, we were also not able to convincingly exclude the second possibility: that RVO at $12 \mathrm{~h}$ influenced the EEG obtained up to $12 \mathrm{~h}$ later. Indeed, a delay in improvement of amplitude-integrated EEG parameters after volume expansion in preterm infants has been reported (23), indicating that cerebral dysfunction is not always rapidly reversible by improved blood flow.

Interestingly, visual review of Figures 1 and 2 show that MAP or RVO values in the lower quartile may be associated with lower EEG values. This may be due to the apparent correlation between the EEG values and hemodynamic values. Alternatively, it may represent a threshold approximating to the lowest quartile for the hemodynamic measurements, below which reduced EEG activity is usual. The concept of hemodynamic thresholds is not new. Previous work has shown LVO threshold $(<100 \mathrm{~mL} / \mathrm{kg} / \mathrm{min})$ was associated with risk of subsequent death in infants with failed circulatory adaptation (24). Evans and Kluckow (25) found that an RVO <150 $\mathrm{mL} / \mathrm{kg} / \mathrm{min}$ was increasingly common in preterm infants with increasing severity of respiratory disease. The absolute measurements in our study are higher; none of the infants studied had an $\mathrm{RVO}<150 \mathrm{~mL} / \mathrm{kg} / \mathrm{min}$. This might be explained by differences in either technical aspects during echocardiography or disease severity. Either way, these observations are interesting and worthy of further study.

Radioisotope scans quantify cerebral blood flow more directly than echocardiography. However, echocardiography is a routine part of NICU practice and flow measurements can be performed by skilled noncardiologist sonographers. In preterm infants, RVO is often a more accurate measure of systemic perfusion than LVO as it is less affected by ductal shunting. SVC flow measurements reflect blood flow returning from the upper body and head and are not influenced by shunting through an open foramen ovale or ductus arteriosus (13). It is puzzling that RVO measurements were more closely related to quantitative EEG measurements than SVC flow measurements. It may be due to inherent variability in SVC flow measurements, the elliptical shape, and reduced rigidity of the 
SVC compared with the right ventricular outflow tract. This variability may make it difficult to discern any relationship with EEG measurements in the small numbers of infants reported here.

$\mathrm{BP}$ is routinely measured in the NICU, and therefore we included measurements of mean, systolic, and diastolic BP in our study. BP and cerebral perfusion have a complex relationship (26), and BP should not be used alone to assess organ perfusion. While infants with more severe intraventricular hemorrhage have been found to have lower MAP over the first $48 \mathrm{~h}$ after birth (27), there are few data to indicate that improving BP measurements improves outcome. We were surprised to find relationships between BP measurements and quantitative EEG measurements at times similar to those found with blood flow measurements. The correlation with diastolic BP at $24 \mathrm{~h}$ was particularly striking in the multivariate analysis (diastolic BP $p=0.0003$ for EEG continuity at the $50 \mu \mathrm{V}$ threshold). These data suggest that gestational age or other factors in the analysis may need to be used to determine thresholds for treatment of diastolic BP. Diastolic BP may be particularly critical in maintaining cerebral perfusion and may be reduced by the development of early left-toright ductal shunting.

In conclusion, current techniques used to monitor cerebral perfusion and function in the NICU are suboptimal, hampering the clinician's ability to assess the impact of clinical management on the developing brain. We have shown that RVO measured $12 \mathrm{~h}$ after birth was related to EEG amplitude and continuity at 12 and $24 \mathrm{~h}$ after birth, and MAP and diastolic BP at 12 and $24 \mathrm{~h}$ were also related to EEG continuity at 12 and $24 \mathrm{~h}$. These data suggest that both low flow and low BP may have an immediate and prolonged impact on EEG activity. However, these results must be interpreted with caution, and, in particular, one should not conclude from this study alone that the relationship between blood flow or BP and cerebral function is causal. Further descriptive and intervention studies with larger numbers of preterm infants will be required to explore this and whether intervention to improve blood flow and BP may improve EEG measurements and, more importantly, long-term neurodevelopmental outcome.

Acknowledgments. We thank the parents and infants who participated in this study and the nursing staff of National Women's NICU: without them nothing would have been achieved. We also acknowledge the contribution of Dr. Michael Navakatikyan to the development of the continuity analysis algorithm.

\section{REFERENCES}

1. Azzopardi D, Guarino I, Brayshaw C, Cowan F, Price-Williams D, Edwards AD, Acolet D 1999 Prediction of neurological outcome after birth asphyxia from early continuous two-channel electroencephalography. Early Hum Dev 55:113-123

2. Thornberg E, Thiringer K 1990 Normal pattern of the cerebral function monitor trace in term and preterm neonates. Acta Paediatr Scand 79:20-25

3. Selton D, Andre M, Hascoet JM 2000 Normal EEG in very premature infants: reference criteria. Clin Neurophysiol 111:2116-2124

4. Inder TE, Buckland L, Williams CE, Spencer C, Gunning MI, Darlow BA, Volpe JJ, Gluckman PD 2003 Lowered electroencephalographic spectral edge frequency predicts the presence of cerebral white matter injury in premature infants. Pediatrics 111:27-33

5. Connell J, de Vries, L, Oozeer R, Regev R, Dubowitz LM, Dubowitz V 1988 Predictive value of early continuous electroencephalogram monitoring in ventilated preterm infants with intraventricular hemorrhage. Pediatrics 82:337-343

6. Menache CC, Bourgeois BF, Volpe JJ 2002 Prognostic value of neonatal discontinuous EEG. Pediatr Neurol 27:93-101

7. Greisen G, Pryds O 1989 Low CBF, discontinuous EEG activity, and periventricular brain injury in ill, preterm neonates. Brain Dev. 11:164-168

8. Van Os S, Klaessens J, Hopman J, Liem D, Van de Bor M 2003 Preservation of electrocortical brain activity during hypoxemia in preterm lambs. Exp Brain Res 151:54-59

9. Reddy K, Mallard C, Guan J, Marks K, Bennet L, Gunning M, Gunn A, Gluckman P, Williams C 1998 Maturational change in the cortical response to hypoperfusion injury in the fetal sheep. Pediatr Res 43:674-682

10. Evans N, Iyer P 1995 Longitudinal changes in the diameter of the ductus arteriosus in ventilated preterm infants: correlation with respiratory outcomes. Arch Dis Child Fetal Neonatal Ed 72:F156-F161

11. Kluckow M, Evans N 2000 Low superior vena cava flow and intraventricular haemorrhage in preterm infants. Arch Dis Child Fetal Neonatal Ed 82:F188-F194

12. Hunt RW, Evans N, Rieger I, Kluckow M 2004 Low superior vena cava flow and neurodevelopment at 3 years in very preterm infants. J Pediatr 145:588-592

13. Kluckow M, Evans N 2000 Superior vena cava flow in newborn infants: a novel marker of systemic blood flow. Arch Dis Child Fetal Neonatal Ed 82:F182-F187

14. Tsai-Goodman B, Martin RP, Marlow N, Skinner JR 2001 The repeatability of echocardiographic determination of right ventricular output in the newborn. Cardiol Young 11:188-194

15. Maynard DE 1979 EEG processing by the Cerebral Function Monitor (CFM). Ann Anesthesiol Fr 20:170-174

16. Parry G, Tucker J, Tarnow-Mordi W, 2003 UK Neonatal Staffing Study Collaborative Group CRIB II: an update of the clinical risk index for babies score. Lancet 361:1789-1791

17. Evans N, Kluckow M 1996 Early ductal shunting and intraventricular haemorrhage in ventilated preterm infants. Arch Dis Child Fetal Neonatal Ed 75:F183-F186

18. Hellstrom-Westas L, Klette H, Thorngren-Jerneck Rosen I 2001 Early prediction of outcome with EEG in preterm infants with large intraventricular hemorrhages. Neuropediatrics 32:319-324

19. Goto K, Wakayama K, Sonoda H, Ogawa T 1992 Sequential changes in electroencephalogram continuity in very premature infants. Electroencephalogr Clin Neurophysiol 82:197-202

20. Selton D, Andre M 1997 Prognosis of hypoxic-ischaemic encephalopathy in fullterm newborns - value of neonatal electroencephalography. Neuropediatrics 28:276-280

21. Biagioni E, Bartalena L, Boldrini A, Pieri R, Cioni G 1999 Constantly discontinuous EEG patterns in full-term neonates with hypoxic-ischaemic encephalopathy. Clin Neurophysiol 110:1510-1515

22. Tan WK, Williams CE, During MJ, Mallard CE, Gunning MI, Gunn AJ, Gluckman PD 1996 Accumulation of cytotoxins during the development of seizures and edema after hypoxic-ischemic injury in late gestation fetal sheep. Pediatr Res 39:791-797

23. Greisen G, Pryds O, Rosen I, Lou H 1988 Poor reversibility of EEG abnormality in hypotensive, preterm neonates. Acta Paediatr Scand 77:785-790

24. Skinner JR, Hunter S, Hey EN 1996 Haemodynamic features at presentation in persistent pulmonary hypertension of the newborn and outcome. Arch Dis Child Fetal Neonatal Ed 74:F26-F32

25. Evans N, Kluckow M 1996 Early determinants of right and left ventricular output in ventilated preterm infants. Arch Dis Child Fetal Neonatal Ed 74:F88-F94

26. Greisen G 2005 Autoregulation of cerebral blood flow in newborn babies. Early Hum Dev 81:423-428

27. Bada HS, Korones SB, Perry EH, Arheart KL, Ray JD, Pourcyrous M, Magill HL, Runyan 3rd, W Somes, GW, Clark FC 1990 Mean arterial blood pressure changes in premature infants and those at risk for intraventricular hemorrhage. J Pediatr 117:607-614 